Article

\title{
Solvothermal synthesis of Co-substituted phosphomolybdate acid encapsulated in the UiO-66 framework for catalytic application in olefin epoxidation
}

\author{
Dianwen $\mathrm{Hu}$, Xiaojing Song, Shujie Wu, Xiaotong Yang, Hao Zhang, Xinyu Chang, Mingjun Jia * \\ College of Chemistry, Jilin University, Changchun 130012, Jilin, China
}

\section{A R T I C L E I N F O}

\section{Article history:}

Received 8 April 2020

Accepted 13 May 2020

Published 5 February 2021

\section{Keywords:}

Polyoxometalate

Metal-organic frameworks

Olefins

Epoxidation

Solvothermal synthesis

\begin{abstract}
A B S T R A C T
Hybrid composites of phosphomolybdic acid@UiO-66 (PMo12@UiO-66) and Co-substituted phosphomolybdic acid@UiO-66 (PMo ${ }_{11} \mathrm{Co@UiO-66)} \mathrm{were} \mathrm{synthesized} \mathrm{using} \mathrm{the} \mathrm{direct} \mathrm{solvothermal}$ method. A variety of characterization results demonstrated that phosphomolybdic acid (PMo12) or Co-substituted phosphomolybdate acid (PMo11Co) clusters are uniformly dispersed in the cages of Zr-based metal-organic UiO-66 frameworks. The catalytic properties of these hybrid composites were investigated by applying the epoxidation of olefins with tert-butyl hydroperoxide as the oxidant. Compared to $\mathrm{PMo}_{12} @ U$ UiO-66, PMo ${ }_{11} \mathrm{Co} @ U i O-66$ showed a much higher catalytic activity and was simply recovered by filtration and reused for at least ten runs without significant loss of catalytic activity. Particularly, PMo11Co@UiO-66 can efficiently convert cyclic olefins like limonenes to epoxides, and its selectivity to 1,2-limonene oxide reached $91 \%$ in the presence of a radical inhibitor such as hydroquinone. The excellent catalytic activity and stability of the hybrid composite PMo11Co@UiO-66 are mainly attributed to the uniform distribution of highly active PMo11Co units within the smaller cages of UiO-66, to the suitable surface polarity of the hybrid composite for facilitating the access of reagents and solvent, and to the strong interface-interactions between the polyoxometalate and the UiO-66 framework.
\end{abstract}

(C) 2021, Dalian Institute of Chemical Physics, Chinese Academy of Sciences. Published by Elsevier B.V. All rights reserved.

\section{Introduction}

Metal-organic frameworks (MOFs) are emerging as a class of crystalline porous materials with potential applications in gas adsorption [1,2], separation [3,4], magnetism [5], nonlinear optical properties [6], and catalysis [7,8]. Particularly, Zr-based metal-organic frameworks (ZrMOFs), which consist of $\mathrm{Zr}_{6} \mathrm{O}_{4}(\mathrm{OH})_{4}$ oxocluster nodes and organic linkers, attracted much attention mainly due to their significant stability. By using ZrMOF materials like UiO-66 and UiO-67 as catalysts or catalyst supports, a variety of highly efficient heterogeneous
ZrMOFs-based catalysts were developed for various catalytic reactions, including Lewis acid, oxidation, biomimetic, hydrogenation, electrocatalytic, and photocatalytic reactions [9-22].

It was reported that by immobilization of polyoxometalate (POM) clusters into Zr-based MOFs, hybrid POM@ZrMOF composites with controllable acidity, redox property, and catalytic performance were obtained [23-29]. In general, POM, including metal-substituted POM, were incorporated into MOFs via simple impregnation [30-32]. However, the supported POM catalysts prepared by this method usually suffer from low catalytic activity owing to the relatively low POM loading and

\footnotetext{
* Corresponding author. Tel: +86-431-85155390; Fax: +86-431-85168420; E-mail: jiamj@jlu.edu.cn This work was supported by the National Natural Science Foundation of China (21173100).

DOI: 10.1016/S1872-2067(20)63665-8 | http://www.sciencedirect.com/science/journal/18722067 | Chin. J. Catal., Vol. 42, No. 2, February 2021
} 
nonuniform distribution of POM clusters. Moreover, POM leaching commonly occurs during the liquid-phase catalytic process mainly due to the instability of the large POM clusters on the solid support surfaces. Therefore, considerable efforts were devoted to developing more effective strategies to synthesize novel POM@MOFs hybrid composites with excellent catalytic activity and stability.

Recently, hybrid POM@MOF (including ZrMOF) composites were obtained by hydrothermal or solvothermal methods directly adding the POM (or precursors) as reactant to the MOF synthesis. For instance, Xie et al. [24] encapsulated 12-tungstophosphoric acid within the cage of UiO-66-2COOH by a one-pot solvothermal method, and then modified the hybrid composite with sulfonated acidic ionic liquids to create an efficient heterogeneous catalyst for converting acidic oil feedstock into biodiesel. Yang et al. [25] solvothermally synthesized a hybrid composite of PW PW $_{12} @$ UiO-66, which exhibited high activity and reusability in the selective oxidation of cyclopentene to glutaraldehyde with $\mathrm{H}_{2} \mathrm{O}_{2}$ as the oxidant. Wang and co-authors [26,27] reported that hybrid composites involving phosphomolybdic acid and UiO-66 were obtained via a one-pot solvothermal method, and a synergistic effect between active Mo species and ZrMOF carriers was demonstrated contributing to a high oxidative desulfurization activity. POM@MOFs hybrid composites derived by this method showed a high dispersion of POM clusters into the matrices of the ZrMOFs support, excellent structure/chemical stability, as well as improved catalytic activity and recyclability caused by the effective interaction between POM and MOFs.

Previously, our group reported the synthesis of hybrid composites based on polyoxomolybdic cobalt (CoPMA) and UiO-67 or UiO-bpy (containing a bipyridine group) by the direct solvothermal method under optimized synthesis conditions [33]. The resultant CoPMA@UiO-bpy hybrid composite exhibited an excellent catalytic activity and stability for olefin epoxidation with $\mathrm{H}_{2} \mathrm{O}_{2}$ or $\mathrm{O}_{2}$ /tert-butyl hydroperoxide as the oxidant. Here, we tried to extend the catalytic application for the family of POM@ZrMOFs composites using olefin epoxidation. Two types of hybrid composites composed of phosphomolybdate acid ( $\mathrm{PMo}_{12}$ ) and Co-substituted phosphomolybdate acid $\left(\mathrm{PMo}_{11} \mathrm{Co}\right)$ units with UiO-66 MOFs were synthesized using the solvothermal method. The resultant POM@ZrMOFs hybrids were characterized by a variety of techniques, and their catalytic performance was investigated for the epoxidation of olefins with tert-butyl hydroperoxide as the oxidant. At the test conditions applied, PMo11Co@UiO-66 showed a much higher catalytic activity than $\mathrm{PMo}_{12} @ U i 0-66$. Moreover, this hybrid catalyst was recycled at least ten times without distinct loss in catalytic activity.

\section{Experimental}

\subsection{Materials}

$\mathrm{Co}\left(\mathrm{NO}_{3}\right)_{2} \cdot 4 \mathrm{H}_{2} \mathrm{O}, \quad N, N^{\prime}$-dimethylformamide (DMF), diethyl ether, methanol, hydrochloric acid (37 wt\%), chloroform, and phosphomolybdic acid (PMo12) were purchased from Sinopharm Chemical Reagent Co., Ltd. $\mathrm{ZrCl}_{4}$, terephthalic acid ( $\left.\mathrm{H}_{2} \mathrm{BDC}\right)$, styrene, 1-octene, 1-decene, cyclohexene, cyclooctene, cyclododecene, cis-stilbene, limonene and $5.5 \mathrm{~mol} \cdot \mathrm{L}^{-1}$ tert-butyl hydroperoxide $(t-\mathrm{BuOOH})$ in $n$-decane were procured from Sigma-Aldrich. All the obtained chemicals were used without further purification.

\subsection{Catalyst preparation}

Co-substituted phosphomolybdic acid $\left(\mathrm{PMo}_{11} \mathrm{Co}\right)$ with the formula $\mathrm{H}_{5} \mathrm{PMo}_{11} \mathrm{O}_{39} \mathrm{Co}_{1} \cdot \times \mathrm{H}_{2} \mathrm{O}$ was prepared according to literature [34]. The hybrid composites of PMo12 and PMo11Co encapsulated in UiO-66 were synthesized based on a literature reported procedure to obtain pure UiO-66 [25]. Typically, $\mathrm{ZrCl}_{4}$ (116 mg), $\mathrm{H}_{2} \mathrm{BDC}$ (83 mg), $37 \mathrm{wt} \%$ hydrochloric acid $(1250 \mu \mathrm{L}$ ) and $\mathrm{PMo}_{12}$ or $\mathrm{PMo}_{11}$ Co were dissolved in DMF (15 mL) and stirred for $1 \mathrm{~h}$. The light green mixture was then transferred into a Teflon-lined stainless-steel autoclave and heated in an oven at $393 \mathrm{~K}$ for $24 \mathrm{~h}$. After cooling down to room temperature, the blue precipitates were filtered, then extracted with ethanol in a Soxhlet apparatus for $24 \mathrm{~h}$ and dried under vacuum at $363 \mathrm{~K}$ overnight. The hybrid composites are denoted as PMo12@UiO-66 and PMo11Co@UiO-66, respectively, and the POM amounts loaded on these catalysts were determined by ICP-OES, as presented in Table 1.

For comparison, a reference catalyst named PMo11Co/UiO-66-imp was prepared by a conventional impregnation method. First, UiO-66 was synthesized according to a literature procedure [25]. Then, $100 \mathrm{mg}$ of UiO-66 was added to $0.5 \mathrm{~mL}$ of a methanol solution of PMo11Co $\left(12 \mathrm{mg} \cdot \mathrm{mL}^{-1}\right)$ at room temperature. After stirring for $2 \mathrm{~h}$, the solids were separated by centrifugation and Soxhlet-extracted with methanol and then dried overnight under vacuum at $363 \mathrm{~K}$ to obtain the reference catalyst $\mathrm{PMo}_{11} \mathrm{Co} / \mathrm{UiO}-66$-imp, respectively. The POM amount of this catalyst was determined by ICP-OES, as provided in Table 1.

\subsection{Characterization}

Table 1

Textural parameters derived from $\mathrm{N}_{2}$ adsorption-desorption profiles as well as element compositions determined by ICP-OES analyses of various materials.

\begin{tabular}{|c|c|c|c|c|c|c|}
\hline Sample & $\begin{array}{l}\text { BET surface area } \\
\left(\mathrm{m}^{2} \cdot \mathrm{g}^{-1}\right)\end{array}$ & $\begin{array}{c}\text { Pore volume } \\
\left(\mathrm{cm}^{3} \cdot \mathrm{g}^{-1}\right)\end{array}$ & $\begin{array}{l}\text { Pore diameter } \\
(\mathrm{nm})\end{array}$ & $\begin{array}{c}\text { POM loading } \\
\left(\mathrm{mmol}^{-1} \mathrm{~g}^{-1} / \mathrm{wt} \%\right)\end{array}$ & $\begin{array}{c}\text { Mo loading } \\
\left(\mathrm{mmol}^{\circ} \mathrm{g}^{-1} / \mathrm{wt} \%\right)\end{array}$ & $\begin{array}{c}\text { Co loading } \\
\left(\mathrm{mmol} \cdot \mathrm{g}^{-1} / \mathrm{wt} \%\right)\end{array}$ \\
\hline UiO-66 & 1202 & 0.58 & 1.9 & - & - & - \\
\hline PMo12@UiO-66 & 994 & 0.53 & 2.1 & $(0.040 / 7.3)$ & $(0.480 / 4.6)$ & - \\
\hline $\mathrm{PMo}_{11} \mathrm{Co} @ U i O-66$ & 991 & 0.51 & 2.0 & $(0.038 / 6.7)$ & $(0.418 / 4.0)$ & $(0.038 / 0.2)$ \\
\hline $\mathrm{PMo}_{11} \mathrm{Co} / \mathrm{UiO}-66$-imp & 956 & 0.47 & 1.9 & $(0.037 / 6.6)$ & $(0.407 / 3.9)$ & $(0.037 / 0.2)$ \\
\hline
\end{tabular}


X-ray powder diffraction (XRD) patterns were collected with a PANalytical B.V. Empyrean X-ray powder diffractometer. The morphology of the composite materials was measured by scanning electron microscopy (SEM) using a HITACHI SU-8020 electron microscope. Transmission electron microscopy (TEM) images were recorded on a JEM-2100F at an accelerating voltage of $200 \mathrm{kV}$ equipped with an energy-dispersive spectroscopy analyzer. Thermogravimetry (TG) was carried out using a NETZSCH STA499F3, heating from 313 to $1173 \mathrm{~K}$ at a rate of 10 $\mathrm{K} \mathrm{min}^{-1}$ under air atmosphere. $\mathrm{N}_{2}$ adsorption-desorption isotherms were measured at $77 \mathrm{~K}$ with a Micromeritics ASAP 2020 automated adsorption analyzer. The surface areas were calculated using the BET (Brunauer-Emmett Teller) method. The pore size distributions were calculated by the NLDFT (non-linear density functional theory) method. Diffuse-reflectance UV-vis (DR-UV-vis) spectra were obtained with a Shimadzu-3600 UV-vis-NIR spectrophotometer. The Fourier-transform infrared (FT-IR) spectra were recorded on a NicoletTM 6700 spectrometer in the range of 4000 to $400 \mathrm{~cm}^{-1}$. X-ray photoelectron spectroscopy (XPS) was performed on a Thermo ESCA LAB 250Xi system with Al $K_{\alpha}$ source. The measured spectra were referenced to the $\mathrm{C} 1 s$ signal at $284.6 \mathrm{eV}$. Inductively coupled plasma-optical emission spectrometry (ICP-OES) analysis was carried out with an iCAP 7600 ICP instrument.

\subsection{Catalytic tests}

In a typical catalytic olefin epoxidation reaction, $1.0 \mathrm{mmol}$ of olefin, $1.0 \mathrm{mmol}$ of $t$-BuOOH, $3 \mathrm{~mL}$ of chloroform (solvent), and $10 \mathrm{mg}$ of catalyst were added to a $10 \mathrm{~mL}$ round-bottomed flask equipped with a reflux condenser. The mixture was stirred for the required time at a specified temperature. The progress of the reaction was monitored using a Shimadzu GC-14C with a HP-5 capillary column. All the oxidation products were identified by comparison with standard samples and finally by gas chromatography-mass spectroscopy applying a GC-MS-QP 2010 plus. After reaction, the used catalyst was isolated by centrifugation and washed repeatedly with chloroform and methanol, and dried overnight at $363 \mathrm{~K}$ under vacuum.

\section{Results and discussion}

\subsection{Synthesis and Characterization}

The synthesis of the PMo ${ }_{12} @ U i O-66$ and PMo ${ }_{11}$ Co@UiO-66 hybrid composites was achieved through the in situ self-assembly of $\mathrm{POM}, \mathrm{ZrCl}_{4}$, and $\mathrm{H}_{2} \mathrm{BDC}$ under solvothermal conditions. The typical synthesis is shown in Scheme 1. According to the coordination modulation mechanism of UiO-66 synthesis revealed in literature $[26,27,35]$, various acids such as saturated monocarboxylic acid (e.g., acetic acid), benzoic acid, and hydrochloric acid could be used as modulator. In previous work [25], it was observed that POM@UiO-66 composites with controllable morphology and crystallinity could easily be obtained when hydrochloric acid was used as modulator. Therefore, the synthesis of PMo12@UiO-66 and

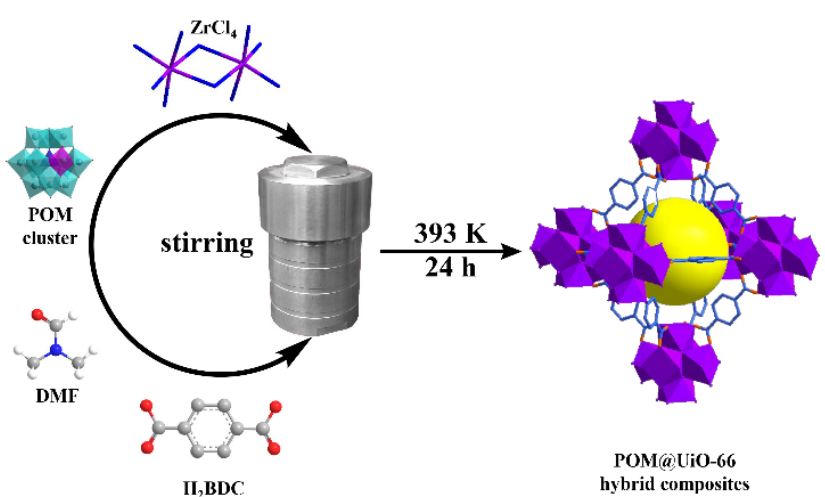

Scheme 1. Typical synthesis of POM@UiO-66 composites.

PMo11Co@UiO-66 was also achieved in the present work using hydrochloric acid as modulator.

Figure 1 shows the XRD patterns of the two POM@UiO-66 composites and UiO-66. The diffraction patterns of PMo12@UiO-66 and PMo11Co@UiO-66 match perfectly with the simulated pattern of UiO-66, confirming that the structure of the ZrMOF host is kept intact after incorporation of the POM units. The reference sample of PMo11Co/UiO-66-imp shows also a similar XRD pattern as the parent UiO-66 (Fig. S1, ESI). Concerning the fact that these composites have relatively high POM loadings, with 7.3 wt\% in PMo12@UiO-66, 6.7 wt\% in PMo ${ }_{11}$ Co@UiO-66, and 6.6 wt\% in PMo ${ }_{11} \mathrm{Co} / \mathrm{UiO}-66$-imp (Table 1 ), the absence of reflections originating from crystalline POMs or Co-related species are an indication that the introduced POMs (including Co species) are either highly dispersed within the MOF host or present in amorphous states.

The SEM images in Figs. 2(a)-(c) show the morphology of UiO-66, PMo12@UiO-66, and PMo11Co@UiO-66. Uniform spherical particles are observed in the images of the support and the hybrid composites. The fact that no noticeable change in morphology between UiO-66 and POM@Ui0-66 occurred implies that the addition of POM units does not affect the crystal growth of the ZrMOFs [25].

The TEM images of PMo11Co@Ui0-66 are shown in Figs. 2(d) and 2(e). It is observed that this material is composed of irregular nanosized particles, and no distinct POM clusters are visible in Fig. 2(e). The energy dispersive spectrometry (EDS) mapping images, displayed in Figs. 2(g)-(i), reveal that Co, $\mathrm{P}$

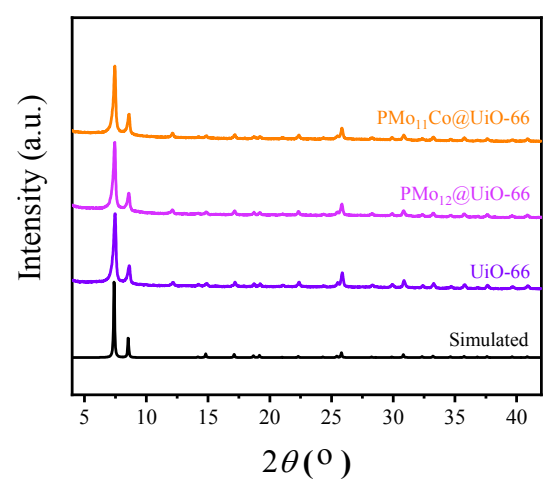

Fig. 1. XRD patterns of simulated UiO-66, UiO-66, and POM@UiO-66 composites. 


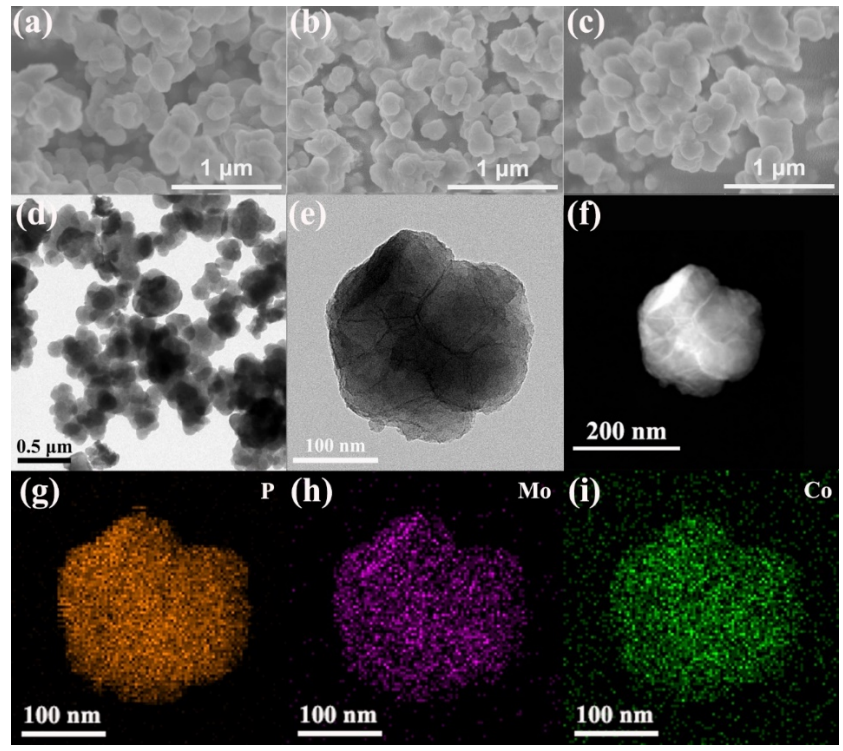

Fig. 2. SEM images of UiO-66 (a), PMo ${ }_{12} @ U i O-66$ (b), and PMo ${ }_{11}$ Co@UiO-66 (c); (d,e) TEM images of PMo ${ }_{11} \mathrm{Co} @ U i O-66 ;(f)$ HAADF-STEM image of PMo ${ }_{11} \mathrm{Co} @ U i O-66$; (g-i) EDS mapping images of PMo ${ }_{11}$ Co@UiO-66.

and Mo are evenly distributed in the PMo11Co@UiO-66 composites. Therefore, it is proposed that the $\mathrm{PMo}_{11} \mathrm{Co}$ clusters are uniformly encapsulated inside the cages of UiO-66.

The thermal stability of the hybrid composites, UiO-66, PMo12@UiO-66, and PMo11Co@Ui0-66, was measured from room temperature to $1073 \mathrm{~K}$ using thermogravimetric (TG) analysis. As shown in Fig. 3, the TG curve of the Ui0-66 sample exhibits two weight loss steps between 313 and $835 \mathrm{~K}$. The first weight loss is attributed to the release of physically adsorbed water and guest DMF molecules. The further weight loss between 795 and $835 \mathrm{~K}$ is ascribed to the framework structure decomposition of MOFs. Further, the TG curve of PMo12@UiO-66 and PMo11Co@UiO-66 show a similar shape to that of UiO-66. Notably, the second weight loss at higher temperature corresponds to the decomposition of the UiO-66 framework and POM clusters into simple oxides. These results

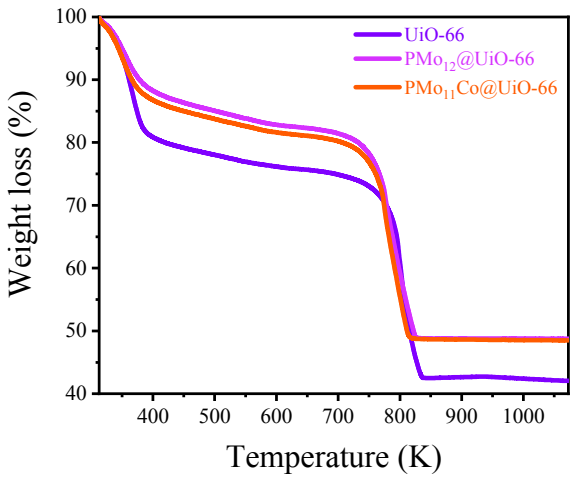

Fig. 3. TG curves of UiO-66, $\mathrm{PMo}_{12} @ U$ UiO-66, and PMo ${ }_{11} \mathrm{Co} @ U i O-66$.

suggest that both the UiO-66 support and POM@ZrMOF composites have excellent thermal stability, which is an important feature for catalytic applications [29,36,55].

The $\mathrm{N}_{2}$ adsorption-desorption isotherms, the pore size distributions, and the textural parameters of hybrid composites are shown in Fig. 4, Fig. S2, and Table 1. All samples display a type I isotherm, indicating the microporous characteristic of these materials. The BET specific surface areas of UiO-66, PMo12@UiO-66, and PMo11Co@UiO-66 are 1202, 994 and 991 $\mathrm{m}^{2} \cdot \mathrm{g}-1$, respectively. In addition, the pore volumes of $\mathrm{PMo}_{12} @ U$ UiO-66 and PMo ${ }_{11} \mathrm{Co} @ U i O-66$ are 0.53 and 0.51 $\mathrm{cm}^{3} \cdot \mathrm{g}^{-1}$, respectively, lower than that of UiO-66 $\left(0.58 \mathrm{~cm}^{3} \cdot \mathrm{g}^{-1}\right)$, which indicates that POM units are distributed inside the cavities of the MOFs. Compared to PMo ${ }_{11}$ Co@UiO-66, the reference sample of PMo11Co/UiO-66-imp exhibits a lower BET specific surface area $\left(956 \mathrm{~m}^{2} \cdot \mathrm{g}^{-1}\right)$ and pore volume $\left(0.47 \mathrm{~cm}^{3} \cdot \mathrm{g}^{-1}\right)$, possibly caused by the uneven distribution of POM clusters in the hybrid composite derived from the impregnation method.

The FT-IR spectra of $\mathrm{PMo}_{12}, \mathrm{PMo}_{11} \mathrm{Co}$, UiO-66, and hybrid POM@UiO-66 composites are shown in Fig. 5. With respect to the PMo12 spectrum, characteristic vibration bands appeared at $1065(\mathrm{P}=0), 966(\mathrm{Mo}=0), 869\left(\mathrm{Mo}-\mathrm{O}_{\mathrm{b}}-\mathrm{Mo}\right)$, and $787 \mathrm{~cm}^{-1}$ (Mo- $\left.\mathrm{O}_{\mathrm{c}}-\mathrm{Mo}\right)$, and are attributed to the Keggin structure of POM clusters [33]. The corresponding vibration bands of the

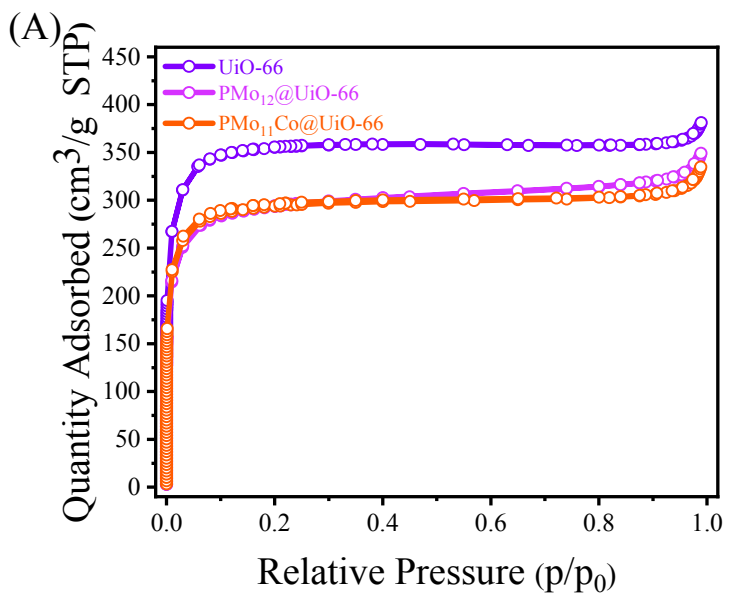

(B)

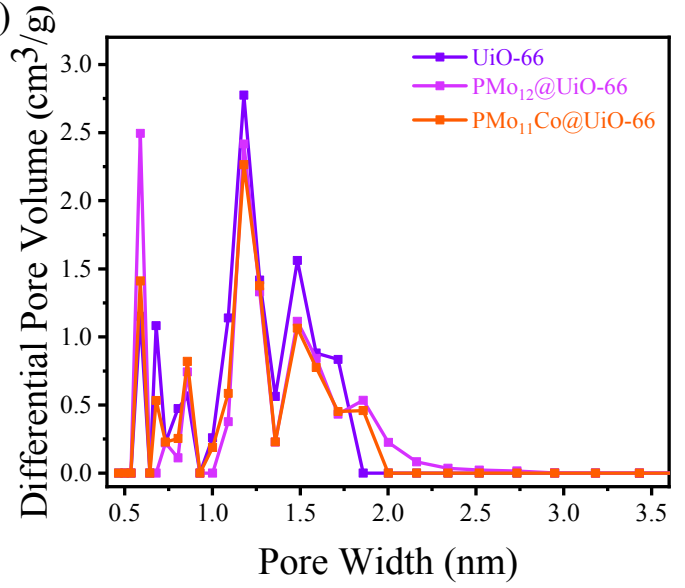

Fig. 4. (A) $\mathrm{N}_{2}$ adsorption-desorption isotherms of UiO-66, PMo12@UiO-66, and PMo11Co@UiO-66 composites; (B) Pore size distribution curves of UiO-66, PMo $12 @ U i O-66$, and PMo ${ }_{11}$ Co@UiO-66 composites. 


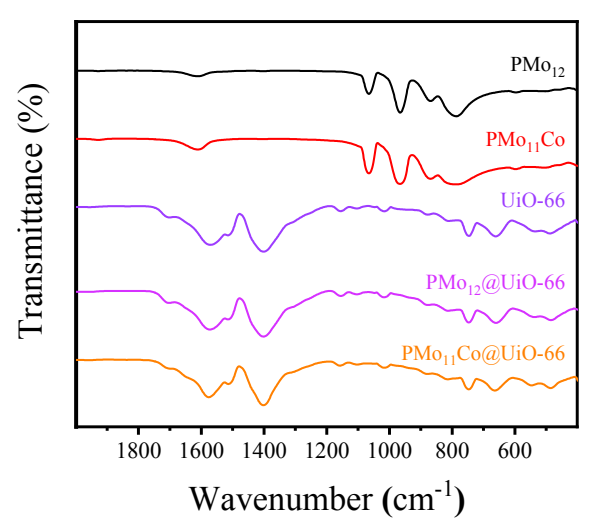

Fig. 5. FT-IR spectra of $\mathrm{PMo}_{12}, \mathrm{PMo}_{11} \mathrm{Co}$, UiO-66, and POM@UiO-66 composites.

PMo ${ }_{11}$ Co sample shifted slightly, which is an indication of the distortion induced by the introduced Co atoms., The observed vibration bands of the UiO-66 support and the hybrid composites between 1300 and $1750 \mathrm{~cm}^{-1}$ are mainly attributed to the carboxylate vibration of the organic linkers. In the FT-IR spectrum of POM@UiO-66, characteristic UiO-66 peaks are prominent and peaks corresponding to POM were insignificant as a result of the relatively low POM loading [25,31]. Notably, Wang and coauthors recently reported that weak IR and Raman signals related to $\mathrm{PMo}_{12}$ with Keggin structure were detected in the spectra of a hybrid material composed of phosphomolybdic acid and UiO-66, which was synthesized by a similar one-pot solvothermal method as adopted in this work [26,27]. Moreover, the presence of Keggin-type PMo12 clusters in the hybrid composite was further confirmed by combining the characterization results of ${ }^{31} \mathrm{P}$ NMR spectra, demonstrating that the basic POM structure remained intact after being incorporated into ZrMOFs using the solvothermal synthesis process [26,27].

Figure 6 depicts the DR-UV-vis spectra of $\mathrm{PMo}_{12}, \mathrm{PMo}_{11} \mathrm{Co}$, UiO-66, and the hybrid composites. As observed in Fig. 6(A), $\mathrm{PMo}_{12}$ exhibits characteristic absorptions at about 217 and 313 $\mathrm{nm}$, which were attributed to the charge transition from $\mathrm{O}^{2-}$ to $\mathrm{Mo}^{6+}$ in $\mathrm{Mo}=\mathrm{O}$ and Mo-O-Mo bonds. PMo11Co presents a spectrum similar to that of $\mathrm{PMo}_{12}$ mainly due to the resemblance of these two materials with respect to structure and composition. A slightly blue-shift of PMo11Co was detected, suggesting that the incorporation of a small cobalt amount into the primary structure of $\mathrm{PMo}_{12}$ resulted in a subtle change in the chemical environment of the Mo species [37]. From Fig. 6(B), it was observed that the UiO-66 support shows a maximum UV absorption $\lambda_{\max }$ at $239 \mathrm{~nm}$, with an absorption edge extended up to $320 \mathrm{~nm}$. Compared to UiO- 66 , the spectra of the hybrid composites present an extra shoulder at approximately 300-400 nm, which is related to the presence of $\mathrm{Mo}^{\mathrm{VI}}$ species in the hybrid composites [38]. Moreover, the broad adsorption in the range of $600-800 \mathrm{~nm}$ corresponded to $d-d$ transitions of $\mathrm{Mo}^{\mathrm{V}}$ species in octahedral coordination, implying that a part of the $\mathrm{MovI}^{\mathrm{VI}}$ species were reduced to $\mathrm{Mo}^{\mathrm{V}}$ species during the formation of the hybrid POM@UiO-66 composites [27].

The Mo $3 d$ XPS profiles of $\mathrm{PMo}_{12}, \mathrm{PMo}_{11} \mathrm{Co}$, and POM@UiO-66 hybrid composites are displayed in Fig. 7(A). For $\mathrm{PMo}_{12}$, the appearance of binding energies at 236.4 and 233.3 $\mathrm{eV}$ are attributed to the $\mathrm{Mo}^{\mathrm{VI}} 3 d_{3 / 2}$ and $\mathrm{MoVI} 3 d_{5 / 2}$, respectively [33,34,39-42]. The binding energies of Mo $3 d$ in PMo11Co were slightly negative shifted (236.2 and $233.1 \mathrm{eV}$ ). As for the hybrid composite of PMo ${ }_{11}$ Co@UiO-66, the binding energies of Mo $3 d$ showed a more negative shift (235.7 and $232.6 \mathrm{eV}$ ), indicating that a partial electron transfer occurred from the UiO-66 frameworks to the POM clusters [34]. Similar results were reported by Wang and co-workers, and they reported that a small amount of $\mathrm{Mo}^{\mathrm{V}}$ species (binding energy at $231.2 \mathrm{eV}$ ) may be formed in PMA/UiO-66 composites (PMA $=\mathrm{PMo}_{12}$ ) due to the presence of strong metal-support interactions (SMSIs) between the PMA and UiO-66 framework [26,27]. In our case, the deconvolution of the Mo $3 d$ XPS profiles of PMo12@UiO-66 and PMo11Co@UiO-66 did not generate distinct $\mathrm{Mo}^{\mathrm{V}}$ signals, indicating that MoVI species are still predominant in this hybrid composite, whereas only trace amounts of $\mathrm{Mo}^{\mathrm{V}}$ species might be present at the interface between POM clusters and the UiO-66 framework. As shown in Fig. 7(B), the XPS profiles of Co $2 p$ for $\mathrm{PMo}_{11}$ Co present two main peaks centered at around 795.5 and $780.2 \mathrm{eV}$, which were ascribed to $\mathrm{Co}^{\mathrm{II}} 2 p_{1 / 2}$ and $\mathrm{Co}^{\mathrm{II}}$ $2 p_{3 / 2}$, respectively [43-45,53,54]. The Co $2 p$ signals of PMo11Co@UiO-66 exhibited a slightly negative shift (795.1 and $779.8 \mathrm{eV}$ ) compared to those of PMo11Co, thus providing further evidence that the chemical environments of the Co substituted POM units change to some extent after being introduced
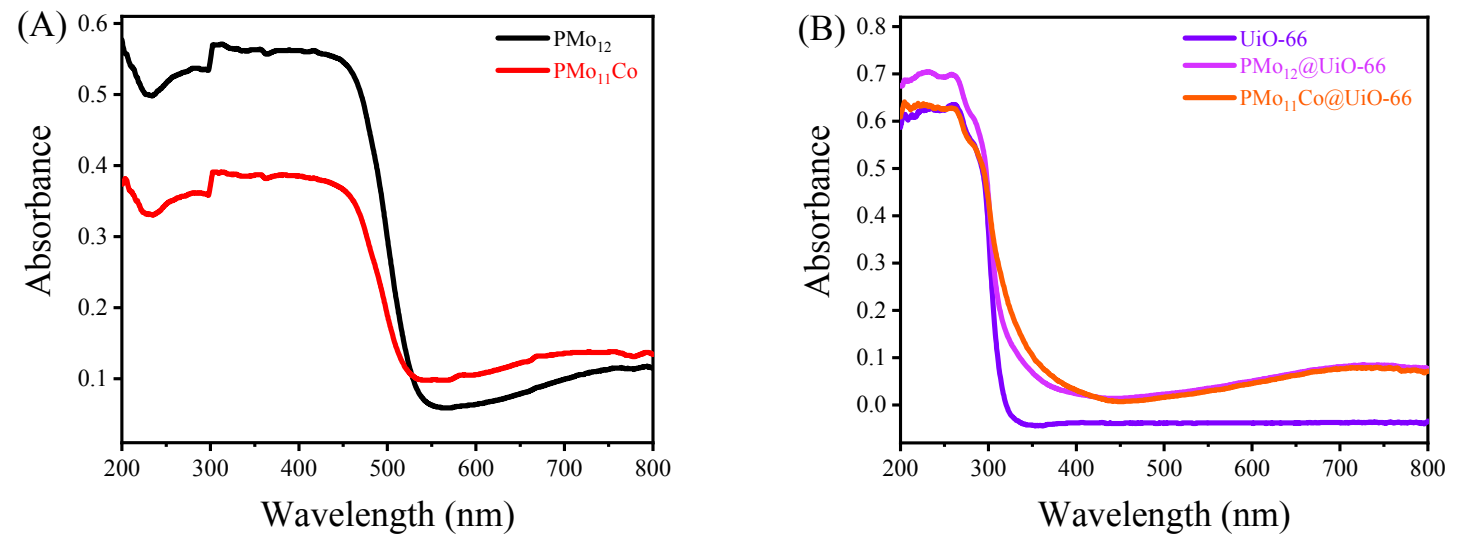

Fig. 6. (A) DR-UV-vis spectra of $\mathrm{PMo}_{12}$ and $\mathrm{PMo}_{11} \mathrm{Co}$; (B) DR-UV-vis spectra of UiO-66 and POM@UiO-66 composites. 

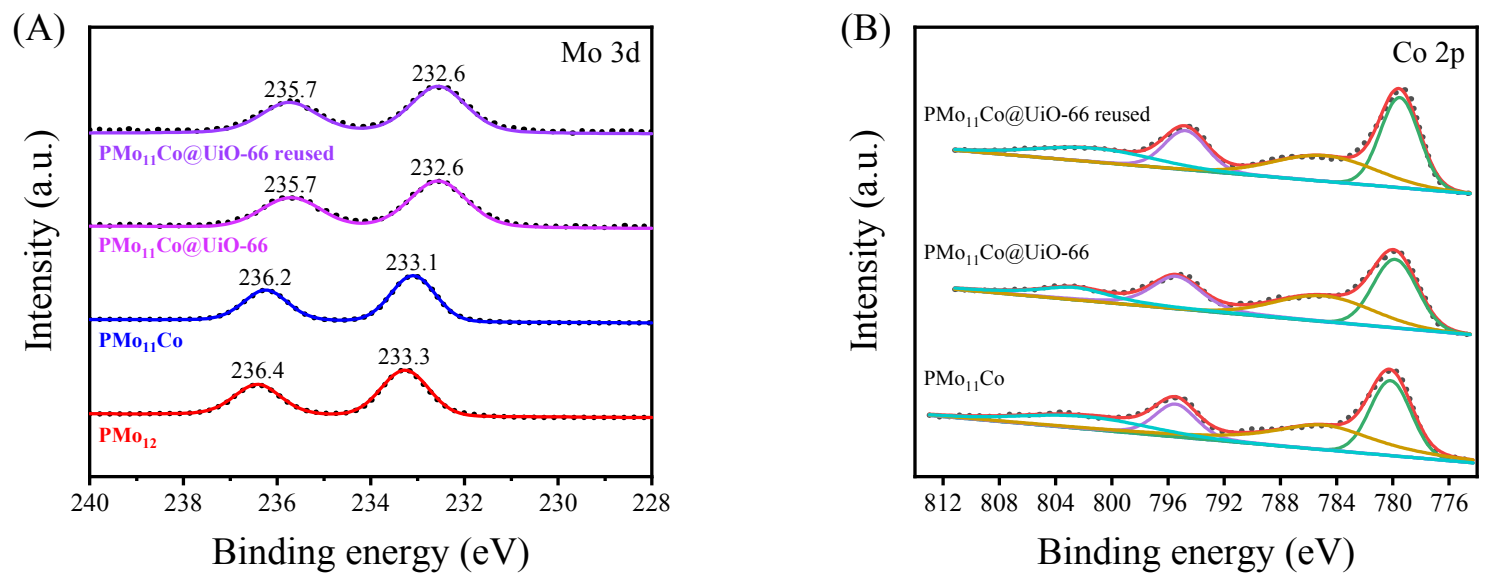

Fig. 7. (A) XPS profiles for the binding energies of Mo $3 d$ in PMo ${ }_{12}, \mathrm{PMo}_{11} \mathrm{Co}, \mathrm{PMo}_{11} \mathrm{Co} @ U \mathrm{UiO}-66$, and reused PMo ${ }_{11} \mathrm{Co} @ U \mathrm{UO}-66$; (B) XPS profiles for the binding energies of Co 2p in PMo11Co, PMo11 Co@UiO-66, and reused PMo11Co@UiO-66.

into the ZrMOFs due to the presence of host-guest interactions. These results suggest that the oxidation states of Mo and Co were only moderately reduced after the POM units were encapsulated into the framework of UiO-66, mainly due to the existence of relatively strong metal-support interactions, which led to a partial electron transfer from the UiO-66 frameworks to POM units.

\subsection{Catalytic performance of POM@UiO-66 composites}

The catalytic properties of the POM@UiO-66 composites were first investigated for the epoxidation of cyclooctene with $t$-BuOOH as the oxidant in the presence of chloroform as the solvent (Table 2 and Fig. S3). Both PMo12@UiO-66 and PMo11Co@UiO-66 catalyze the epoxidation of cyclooctene, whereas a relatively higher catalytic activity was observed for the Co-substituted catalyst sample. Based on the calculated TOF values of various catalysts listed in Table 2 , it is observed that the activity of PMo ${ }_{11}$ Co@UiO-66 (TOF $19 \mathrm{~h}^{-1}$ at $334 \mathrm{~K}$ ) is comparable to that of POM-based catalysts like Mo(CO) $)_{3}$ L@UiO-66 (TOF $19 \mathrm{~h}^{-1}$ at $353 \mathrm{~K}$ ) reported in literature, but is lower than that of our previously reported PMo ${ }_{12} @$ COF-300 (TOF $44 \mathrm{~h}^{-1}$ at $334 \mathrm{~K})[40,46,47]$. It should be mentioned that the reference catalyst $\mathrm{PMo}_{11} \mathrm{Co} / \mathrm{UiO}-66$-imp, prepared by the impregnation method, is also reasonably active for the epoxidation reaction (Fig. S4). However, this catalyst is not stable at the test condition, serious leaching of POM species was detected during the reaction (Fig. S5). PMo11Co@UiO-66 provided a much higher stability against leaching proven by a hot filtration experiment, demonstrating the true heterogeneous nature of this hybrid catalyst (Fig. 8). Additional experiments demonstrated that PMo11Co@UiO-66 was easily recycled by simple filtration, washing with chloroform and drying at $363 \mathrm{~K}$. The catalytic activity was nearly unchanged after the tenth run, indicating the excellent recyclability of the catalyst.

The high stability of $\mathrm{PMo}_{11} \mathrm{Co} @ U i \mathrm{U}-66$ was confirmed by further characterization of the used catalysts, including XRD, FT-IR, DR-UV-vis and XPS (Fig. S6-S8). There were no significant differences in the spectra between the fresh and the used catalyst. The appearance of weak vibrations at 2948 and 2859 $\mathrm{cm}^{-1}$ in the FT-IR spectrum of the used catalyst was attributed to the existence of a small amount of reactants or products adsorbed on the surface of the used PMo ${ }_{11}$ Co@UiO-66 catalyst. Notably, the broad absorption peak in the range of $600-800$ nm in the DR-UV-vis spectrum of the fresh PMo ${ }_{11}$ Co@UiO-66 catalyst disappeared after the catalytic test, which was also

Table 2

Cyclooctene epoxidation performance of various catalyst samples ${ }^{\mathrm{a}}$.

\begin{tabular}{|c|c|c|c|c|c|c|}
\hline Entry & Catalyst & Amount of catalyst (mg) & Time (h) & Conversion (\%) & $\mathrm{TOF}^{\mathrm{b}}\left(\mathrm{h}^{-1}\right)$ & Related work \\
\hline 1 & Blank & - & 6 & 3 & - & This work \\
\hline 2 & UiO-66 & 10 & 6 & 3 & - & This work \\
\hline 3 & PMo12@UiO-66 & 10 & 6 & 32 & 11 & This work \\
\hline 4 & PMo ${ }_{11} \mathrm{Co} @ U i O-66$ & 10 & 6 & 52 & $19 \mathrm{c}$ & This work \\
\hline 5 & $\mathrm{PMo}_{11} \mathrm{Co} / \mathrm{UiO}-66$-imp & 10 & 6 & 40 & $15^{c}$ & This work \\
\hline 6 & PMo12@COF-300f & 10 & 3 & 63 & 44 & [40] \\
\hline 7 & $\mathrm{Mo}(\mathrm{CO})_{3}-\mathrm{L} @ U \mathrm{UiO}-66^{\mathrm{d}}$ & 100 & 4.5 & 98 & 19 & [46] \\
\hline 8 & $\mathrm{PMo}_{12} @$ meso-organosilicates e & 100 & 6 & 58 & 4 & [47] \\
\hline
\end{tabular}

a Reaction condition: olefin $1.0 \mathrm{mmol}, t$-BuOOH $1.0 \mathrm{mmol}$, chloroform $3 \mathrm{~mL}$, reaction temperature $334 \mathrm{~K}$

b TOF is expressed in $\mathrm{mol}(\mathrm{cyclooctene}) \cdot \mathrm{mol}(\mathrm{Mo})^{-1} \cdot \mathrm{h}^{-1}$

c TOF is expressed in mol(cyclooctene) $\operatorname{mol}(\mathrm{Mo} \& \mathrm{Co})^{-1} \cdot \mathrm{h}^{-1}$

d Reaction condition: cyclooctene $1.0 \mathrm{mmol}, t$-BuOOH $2.0 \mathrm{mmol}$, acetonitrile $3 \mathrm{~mL}$, reaction temperature $353 \mathrm{~K}$.

e Reaction condition: cyclooctene $5.0 \mathrm{mmol}, t$-BuOOH $5.0 \mathrm{mmol}, n$-dodecane $5.0 \mathrm{mmol}$ (internal standard), chloroform $10 \mathrm{~mL}$, reaction temperature $323 \mathrm{~K}$.

${ }^{\mathrm{f}}$ Reaction condition: cyclooctene $1.0 \mathrm{mmol}, t$-BuOOH $1.0 \mathrm{mmol}$, chloroform $2 \mathrm{~mL}$, reaction temperature $334 \mathrm{~K}$. 
(A)

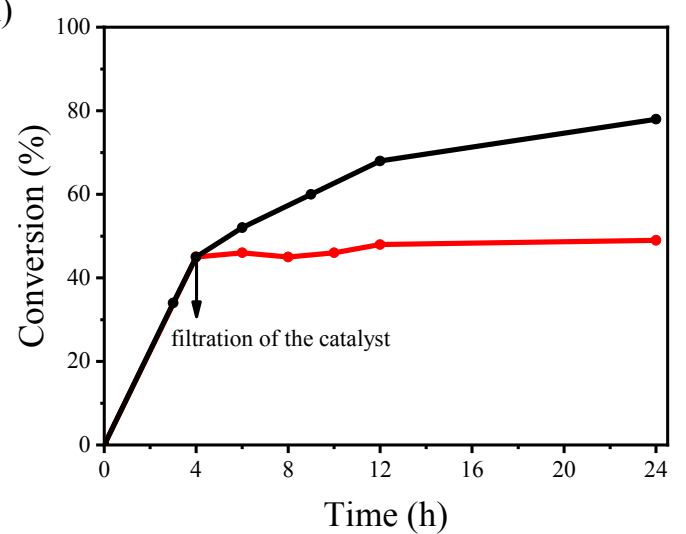

(B)

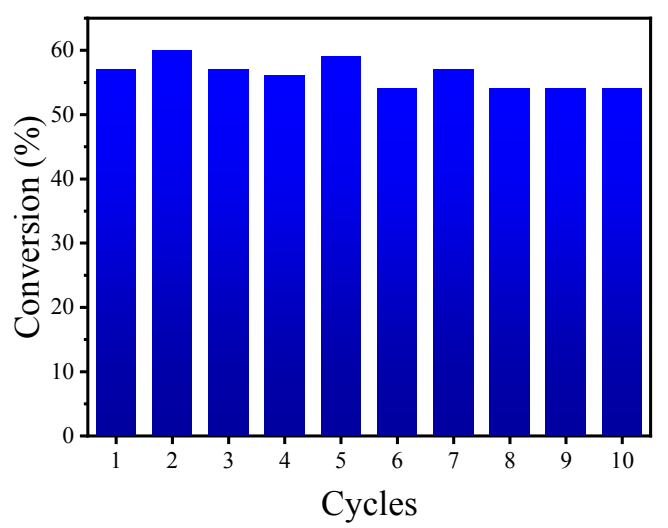

Fig. 8. Leaching (A) and recycling (B) experiments of $\mathrm{PMo}_{11} \mathrm{Co} @ U i O-66$. Reaction conditions: cyclooctene $5.0 \mathrm{mmol}$, $t$-BuOOH 5.0 mmol, PMo ${ }_{11}$ Co@UiO-66 50 mg, solvent 15 ml, 334 K, 6 h. All epoxide selectivity was greater than 99\%.

related to the adsorption of reactants/products on the surface of the used PMo11Co@UiO-66 catalyst [34].

The influence of solvents on the catalytic properties of PMo11Co@UiO-66 was investigated by testing different solvents for the epoxidation reaction. As shown in Fig. 9, the catalytic activity of $\mathrm{PMo}_{11} \mathrm{Co} @ U i \mathrm{U}-66$ is solvent-dependent, decreasing in the order of tetrachloromethane $\approx$ chloroform $>$ toluene $>$ acetonitrile $>$ ethanol. It was proposed that highly coordinating solvents such as acetonitrile and ethanol may considerably decrease the catalytic activity, since they compete with $t$-BuOOH to bind to the metal centers [57-59]. Besides, the relatively strong polarity of these solvents easily entrap them in the polar channel/cavity of UiO-66, thus considerably decrease the accessibility of the reagents to the encapsulated POM sites (olefin and $t$-BuOOH), finally resulting in a poor activity (even no reactivity) of the hybrid PMo11Co@UiO-66 catalyst. Hereafter, chloroform was chosen as solvent to further study the catalytic property of $\mathrm{PMo}_{11} \mathrm{Co} @ U i 0-66$ for the epoxidation of other olefins.

Additional experiments showed that PMo11Co@UiO-66 is also catalytically active for epoxidizing cyclooctene with $\mathrm{H}_{2} \mathrm{O}_{2}$ as the oxidant (Table S1). However, this catalyst was instable at

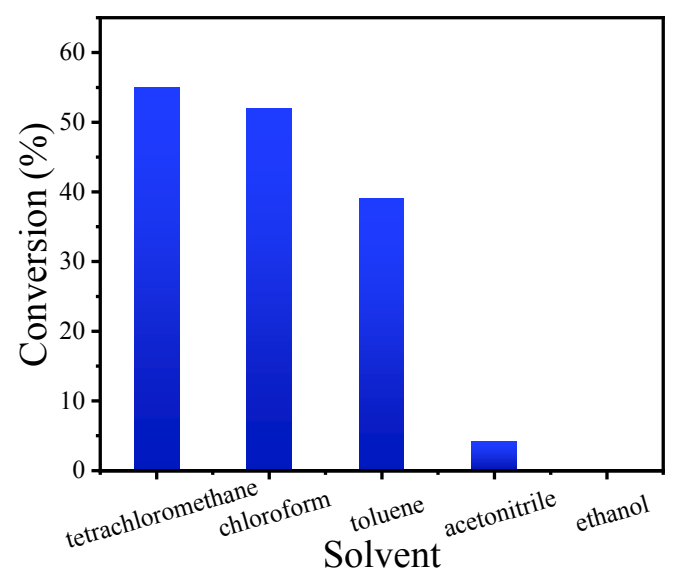

Fig. 9. Solvent effect on cyclooctene epoxidation. Reaction conditions: cyclooctene $1.0 \mathrm{mmol}, t$-BuOOH $1.0 \mathrm{mmol}, \mathrm{PMo}_{11} \mathrm{Co} @ U \mathrm{UiO}-6610 \mathrm{mg}$, solvent $3 \mathrm{ml}, 334 \mathrm{~K}, 6 \mathrm{~h}$. Selectivity for the epoxide is greater than $99 \%$. the tested condition, and leaching of active species was detected because of the strong complexing capability of $\mathrm{H}_{2} \mathrm{O}_{2}$. This feature differed from our previously reported CoPMA@UiO-bpy catalyst, which was active and stable with respect to the $\mathrm{H}_{2} \mathrm{O}_{2}$-mediated epoxidation reaction [33]. These results suggested that changing the bridged ligands in ZrMOFs considerably affected the catalytic performance of the POM@ZrMOF catalysts.

As shown in Table 3, PMo11 Co@UiO-66 is catalytically active for the epoxidation of a wide range of olefins, including various cyclic and linear olefins. Of these, linear olefins like 1-octene and 1-decene were converted to the corresponding epoxides at relative low conversion. Cyclic olefins such as cyclohexene and cyclododecene were oxidized at higher conversions. However, more side products like aldehydes, enols, and ketenes were

Table 3

Epoxidation of olefins catalyzed by PMo11Co@UiO-66 ${ }^{\text {a }}$.

Entry

a Reaction conditions: olefin $1 \mathrm{mmol}, t$-BuOOH $1 \mathrm{mmol}$, catalyst $10 \mathrm{mg}$, chloroform $3 \mathrm{~mL}$, reaction temperature $334 \mathrm{~K}$, and reaction time $12 \mathrm{~h}$.

b $1.0 \mathrm{mmol}$ chlorobenzene was added as internal standard.

c Conversion and selectivity were determined by GC-MS.

${ }^{\mathrm{d}}$ By products like aldehydes, enol, ketene, etc.; see Scheme S1.

e TOF is expressed in $\operatorname{mol}($ olefin $) \cdot \operatorname{mol}\left(\mathrm{Mo} \& \mathrm{Co}^{-1} \cdot \mathrm{h}^{-1}\right.$. 


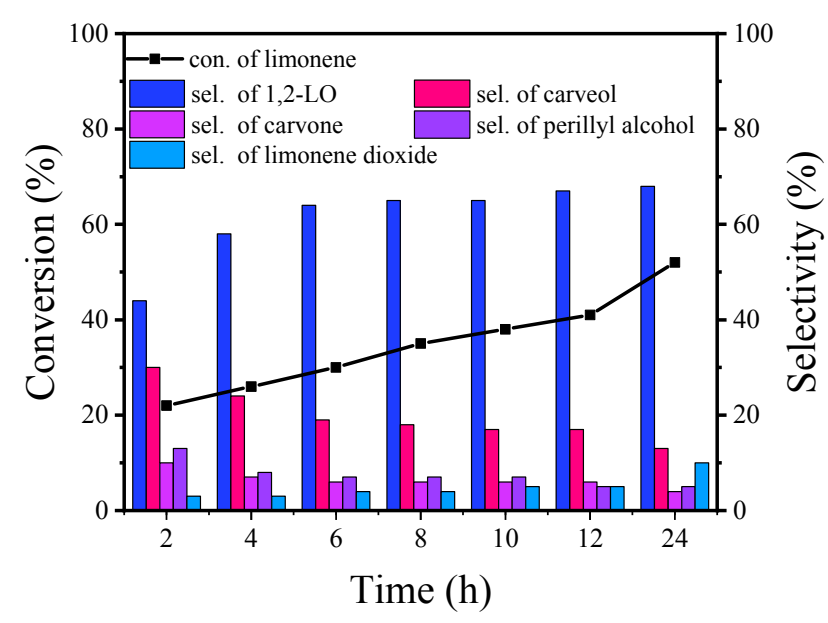

Fig. 10. Conversion and selectivity during selective limonene oxidation. Reaction conditions: limonene $10 \mathrm{mmol}, t$-BuOOH $20 \mathrm{mmol}$, catalyst $100 \mathrm{mg}$, chloroform $30 \mathrm{~mL}$, reaction temperature $334 \mathrm{~K}$.

detected (Scheme S1). PMo ${ }_{11}$ Co@UiO-66 is also active for the epoxidation of cis-stilbene showing $42 \%$ conversion and $69 \%$ selectivity. The formation of multiple side products implies that various catalytic oxidation pathways are possible, as discussed later.

The epoxidation of limonene was investigated to further understand the nature of the active sites of PMo11Co@UiO-66 and the main paths of the oxidation reactions (see Fig. 10). Limonene has two types of double bonds, making it an ideal compound to reveal the catalytic mechanism. As shown in Scheme 2, various products including 1,2-limonene oxide, limonene dioxide, carveol, carvone, and perillyl alcohol were formed in the catalytic limonene oxidation, which are highly dependent on the nature of the active sites of the catalysts as well as the operating conditions. As shown in Fig 10, a relative high selectivity (64\%) to 1,2-limonene oxide, the most valuable product, was achieved over PMo11Co@UiO-66 at the tested condition. In terms of regioselectivity, the $1,2-\mathrm{C}=\mathrm{C}$ double bond is much easier oxidized to form the oxirane ring than the 8,9-C=C double bond, suggesting that the oxygen transfer preferentially takes place at the electron-rich endocyclic position [48-51].

In general, a peroxidic oxygen donor such as $t$-BuOOH might be directly activated by Mo-containing POM catalysts to form a Mo-OOR adduct, which is regarded as an active intermediate generating the epoxide (path 1). Besides, the peroxidic oxygen donor might also be homolytically activated to form a radical species, which can result in the formation of allylic oxidation products (path 2) [52]. In the present case, the

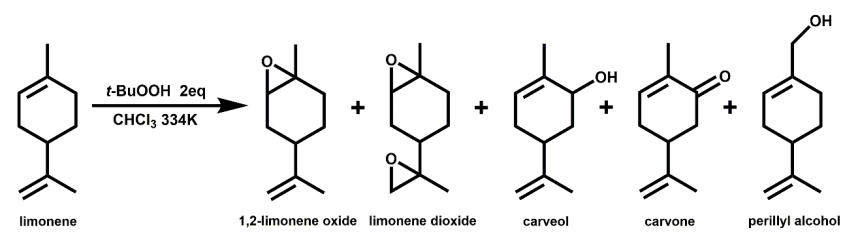

Scheme 2. Main products of selective limonene oxidation.
PMo11Co@UiO-66 catalyst exhibits a considerable high selectivity to both the epoxides and the allylic oxidation products oxidizing cyclic olefins like limonene, revealing that the two catalytic oxidation pathways (path 1 and path 2) are competitive, as described in Scheme 3.

Further control experiments showed that the limonene oxidation over PMo11Co@UiO-66 was partially inhibited if hydroquinone was introduced as a radical scavenger. In this case (Figs. S9 and S10), the limonene conversion slightly decreased (i.e., from $22 \%$ to $13 \%$ after $2 \mathrm{~h}$ of reaction), while the selectivity to epoxides significantly increased (from $44 \%$ to $91 \%$ ). These results provided strong evidence that the homolytic radical-mediated pathway was indeed active in the olefin oxidation process, which can be prevented by introducing a radical scavenger.

Previously, it was reported that the substitution of phosphomolybdic acid by transition metals (TMs) like Ti, V, Co, Nb, and $\mathrm{Rh}$ considerably improves the catalytic oxidation ability of the POM catalysts [33,34,51-54]. Introducing a small amount of transition metals might adjust the electron density of the neighboring Mo species forming TM-O-Mo bonds, thus activating the olefin epoxidation activity [34]. Moreover, recent literature work that combined a variety of characterization results with DFT calculations revealed that substituted transition metals such as $\mathrm{Ti}$ or $\mathrm{Nb}$ can act as a new active site to directly activate oxidants like $t$ - $\mathrm{BuOOH}$ and $\mathrm{H}_{2} \mathrm{O}_{2}$ [56,60,61]. In our case, the electron density of Mo atoms in POM decreased slightly after introducing a small amount of Co, as suggested by the XPS results. Meanwhile, the chemical environments of the Co atoms changed too, due to the formation of Co-O-Mo bonds. Therefore, it is proposed that the relatively high catalytic activity of PMo ${ }_{11}$ Co@UiO-66 compared to that of PMo ${ }_{12} @ U i O-66$ is mainly attributed to the formation of Co-containing active sites (i.e., Co-O-Mo species), which directly activate $t$-BuOOH to produce highly active hydroperoxo species.

By comparing the catalytic properties of the solvothermally synthesized PMo11Co@UiO-66 and $\mathrm{PMo}_{11} \mathrm{Co} / \mathrm{UiO}-66$-imp prepared by the impregnation-method (Table 2 and Fig. S4), it was determined that the POM units dispersed on the surface were not stable during the liquid-phase catalytic oxidation process, whereas the confined POM units in the UiO-66 cage provided a much higher stability against active site leaching. Based on literature and our previous work [25,33], the high stability of PMo11Co@UiO-66 was mainly attributed to the spatial confinement of the PMo11Co units within the cages of the UiO-66

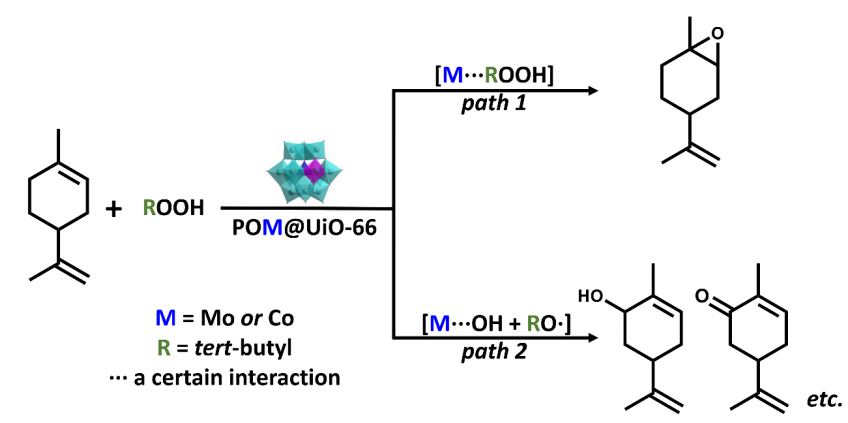

Scheme 3. Proposed oxygen activation mechanism of $t$-BuOOH. 
frameworks. Given the size of PMo ${ }_{11}$ Co (about $10 \AA$ ), it just fits the size of the superoctahedral cages (11 A) of the UiO-66 MOFs. Therefore, the octahedral cages with smaller triangular windows (5-7 Å) can encapsulate the POM units, and effectively prevent the loss of POM during the catalytic tests. Interactions between POM units and the UiO-66 frameworks, as proven by XPS characterization results, also play a positive role in generating a highly stable hybrid composite catalyst.

On other hand, the window of the Ui0-66 framework is big enough to allow reactants and products to enter or exit the cage, which means that the POM active sites located inside the cage of MOFs are easily accessible for the catalytic reaction. Other factors, such as the surface polarity of the POM@ZrMOF catalysts are also quite important to achieve a high catalytic performance, which polarity can significantly influence the diffusion of reactants/products. It seems that the PMo11Co@UiO-66 polarity is beneficial for the olefin epoxidations with $t$-BuOOH as the oxidant using chloroform as a solvent.

\section{Conclusions}

In this work, the hybrid composites of PMo11Co@UiO-66 and PMo12@UiO-66 were synthesized by a one-pot solvothermal method. Characterization results demonstrated that the primary crystalline structure of the UiO-66 support remains intact after introducing POM into the cages of the MOF supports. Relatively strong metal-support interactions are present between the POM units and UiO-66 frameworks. The PMo11Co@Ui0-66 catalyst shows excellent catalytic activity, selectivity, and stability during the epoxidation of a variety of olefins with $t$-BuOOH as the oxidant. The UiO-66 framework stabilizes the incorporated PMo11Co units by spatial confinement as well as by the interaction between the POM units and the ZrMOF framework. Further work is currently underway to study the catalytic performance of these hybrid composites for molecular oxygen-mediated olefin epoxidation reactions in order to extend their catalytic application in oxidation processes.

\section{Conflict of Interest}

The authors declare no conflict of interest.

\section{References}

[1] M. Eddaoudi, J. Kim, N. Rosi, D. Vodak, J. Wachter, M. O’Keeffe, O. M. Yaghi, Science, 2002, 295, 469-472.

[2] J. W. Yoon, S. H. Jhung, Y. K. Hwang, S. M. Humphrey, P. T. Wood, J. S. Chang, Adv. Mater., 2007, 19, 1830-1834.

[3] J. R. Li, R. J. Kuppler, H. C. Zhou, Chem. Soc. Rev., 2009, 38, 1477-1504.

[4] R. Matsuda, R. Kitaura, S. Kitagawa, Y. Kubota, R. V. Belosludov, T. C. Kobayashi, H. Sakamoto, T. Chiba, M. Takata, Y. Kawazoe, Y. Mita, Nature, 2005, 436, 238-241.

[5] G. J. Halder, C. J. Kepert, B. Moubaraki, K. S. Murray, J. D. Cashion, Science, 2002, 298, 1762-1765.

[6] O. R. Evans, W. Lin, Acc. Chem. Res., 2002, 35, 511-522.

[7] J. Liu, L. Chen, H. Cui, J. Zhang, L. Zhang, C. Y. Su, Chem. Soc. Rev., 2014, 43, 6011-6061.

[8] L. Jiao, Y. Wang, H. L. Jiang, Q. Xu, Adv. Mater., 2018, 30, e1703663.

[9] S. T. Gao, W. Liu, C. Feng, N. Z. Shang, C. Wang, Catal. Sci. Technol., 2016, 6, 869-874.

[10] L. Shen, W. Wu, R. Liang, R. Lin, L. Wu, Nanoscale, 2013, 5, 9374-9382.

[11] C. S. Hinde, W. R. Webb, B. K. Chew, H. R. Tan, W. H. Zhang, T. S. Hor, R. Raja, Chem. Commun., 2016, 52, 6557-6560.

[12] J. C. Wang, Y. H. Hu, G. J. Chen, Y. B. Dong, Chem. Commun., 2016, 52, 13116-13119.

[13] M. Kaposi, M. Cokoja, C. H. Hutterer, S. A. Hauser, T. Kaposi, F. Klappenberger, A. Pothig, J. V. Barth, W. A. Herrmann, F. E. Kuhn, Dalton Trans., 2015, 44, 15976-15983.

[14] L. Chen, R. Luque, Y. Li, Dalton Trans., 2018, 47, 3663-3668.

[15] F. Zhang, S. Zheng, Q. Xiao, Y. Zhong, W. Zhu, A. Lin, M. Samy El Shall, Green Chem., 2016, 18, 2900-2908.

[16] M. W. Logan, Y. A. Lau, Y. Zheng, E. A. Hall, M. A. Hettinger, R. P. Marks, M. L. Hosler, F. M. Rossi, Y. Yuan, F. J. Uribe-Romo, Catal. Sci. Technol., 2016, 6, 5647-5655.

[17] R. Insyani, D. Verma, S. M. Kim, J. Kim, Green Chem., 2017, 19, 2482-2490.

[18] J. Chen, K. Li, L. Chen, R. Liu, X. Huang, D. Ye, Green Chem., 2014, 16, 2490-2499.

[19] H. G. T. Nguyen, L. Mao, A. W. Peters, C. O. Audu, Z. J. Brown, O. K.

\section{Graphical Abstract}

Chin. J. Catal., 2021, 42: 356-366 doi: 10.1016/S1872-2067(20)63665-8

Solvothermal synthesis of Co-substituted phosphomolybdate acid encapsulated in the UiO-66 framework for catalytic application in olefin epoxidation

Dianwen Hu, Xiaojing Song, Shujie Wu, Xiaotong Yang, Hao Zhang, Xinyu Chang, Mingjun Jia *

Jilin University

Hybrid composites based on Co-substituted phosphomolybdic acid ( $\left.\mathrm{PMo}_{11} \mathrm{Co}\right)$ and UiO-66 were synthesized by the direct solvothermal method.PMo11Co@UiO-66 showed high catalytic activity and stability for the epoxidation of a variety of olefins with $t$ - $\mathrm{BuOOH}$ as

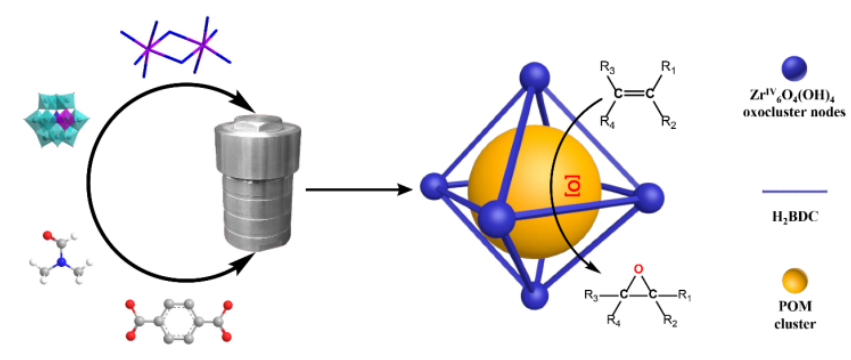
the oxidant. 
Farha, J. T. Hupp, S. T. Nguyen, Catal. Sci. Technol., 2015, 5, 4444-4451.

[20] A. H. Valekar, K. H. Cho, S. K. Chitale, D. Y. Hong, G. Y. Cha, U. H. Lee, D. W. Hwang, C. Serre, J. S. Chang, Y. K. Hwang, Green Chem., 2016, $18,4542-4552$.

[21] M. Lammert, M. T. Wharmby, S. Smolders, B. Bueken, A. Lieb, K. A. Lomachenko, D. D. Vos, N. Stock, Chem. Commun., 2015, 51, 12578-12581.

[22] F. Nouar, M. I. Breeze, B. C. Campo, A. Vimont, G. Clet, M. Daturi, T. Devic, R. I. Walton, C. Serre, Chem. Commun., 2015, 51, 14458-14461.

[23] A. Dhakshinamoorthy, A. Santiago-Portillo, A. M. Asiri, H. Garcia, ChemCatChem, 2019, 11, 899-923.

[24] W. Xie, F. Wan, Chem. Eng. J., 2019, 365, 40-50.

[25] X. L. Yang, L. M. Qiao, W. L. Dai, Microporous Mesoporous Mater., 2015, 211, 73-81.

[26] X. M. Zhang, Z. Zhang, B. Zhang, X. Yang, X. Chang, Z. Zhou, D. H. Wang, M. H. Zhang, X. H. Bu, Appl. Catal. B, 2019, 256, 117804.

[27] X. Chang, X. F. Yang, Y. Qiao, S. Wang, M. H. Zhang, J. Xu, D. H. Wang, X. H. Bu, Small, 2020, DOI: 10.1002/smll.201906432, 1906432.

[28] C. T. Buru, P. Li, B. L. Mehdi, A. Dohnalkova, A. E. P. Prats, N. D. Browning, K. W. Chapman, J. T. Hupp, O. K. Farha, Chem. Mater., 2017, 29, 5174-5181.

[29] W. Salomon, C. Roch-Marchal, P. Mialane, P. Rouschmeyer, C. Serre, M. Haouas, F. Taulelle, S. Yang, L. Ruhlmann, A. Dolbecq, Chem. Commun., 2015, 51, 2972-2975.

[30] G. Férey, C. Mellot-Draznieks, C. Serre, F. Millange, J. Dutour, S. Surblé, I. Margiolaki, Science, 2005, 309, 2040-2042.

[31] W. Salomon, F. J. Yazigi, C. Roch-Marchal, P. Mialane, P. Horcajada, C. Serre, M. Haouas, F. Taulelle, A. Dolbecq, Dalton Trans., 2014, 43, 12698-12705.

[32] N. V. Maksimchuk, O. A. Kholdeeva, K. A. Kovalenko, V. P. Fedin, Isr. J. Chem., 2011, 51, 281-289.

[33] X. Song, D. Hu, X. Yang, H. Zhang, W. Zhang, J. Li, M. Jia, J. Yu, ACS Sustain. Chem. Eng., 2019, 7, 3624-3631.

[34] X. Song, W. Zhu, K. Li, J. Wang, H. Niu, H. Gao, W. Gao, W. Zhang, J. Yu, M. Jia, Catal. Today, 2016, 259, 59-65.

[35] A. Schaate, P. Roy, A. Godt, J. Lippke, F. Waltz, M. Wiebcke, P. Behrens, Chem. Eur. J., 2011, 17, 6643-6651.

[36] B. Tu, Q. Pang, H. Xu, X. Li, Y. Wang, Z. Ma, L. Weng, Q. Li, J. Am. Chem. Soc., 2017, 139, 7998-8007.

[37] J. She, Z. Fu, J. Li, B. Zeng, S. Tang, W. Wu, H. Zhao, D. Yin, S. R. Kirk, Appl. Catal. B, 2016, 182, 392-404.

[38] N. Afzali, R. Kardanpour, F. Zadehahmadi, S. Tangestaninejad, M. Moghadam, V. Mirkhani, A. Mechler, I. M. Baltork, M. Bahadori, Appl. Organomet. Chem., 2019, 33, e5225.
[39] X. Song, Y. Yan, Y. Wang, D. Hu, L. Xiao, J. Yu, W. Zhang, M. Jia, Dalton Trans., 2017, 46, 16655-16662.

[40] W. Gao, X. Sun, H. Niu, X. Song, K. Li, H. Gao, W. Zhang, J. Yu, M. Jia, Microporous Mesoporous Mater., 2015, 213, 59-67.

[41] X. Song, W. Zhu, Y. Yan, H. Gao, W. Gao, W. Zhang, M. Jia, J. Mol. Catal. A, 2016, 413, 32-39.

[42] X. Song, W. Zhu, Y. Yan, H. Gao, W. Gao, W. Zhang, M. Jia, Microporous Mesoporous Mater., 2017, 242, 9-17.

[43] C. Qin, A. Fan, D. Ren, C. Luan, J. Yang, Y. Liu, X. Zhang, X. Dai, M. Wang, Electrochim. Acta, 2019, 323, 134756.

[44] M. C. Biesinger, B. P. Payne, A. P. Grosvenor, L. W. M. Lau, A. R. Gerson, R. S. C. Smart, Appl. Surf. Sci., 2011, 257, 2717-2730.

[45] Q. Zhang, J. Zhang, H. Yang, Y. Dong, Y. Liu, L. Yang, D. Wei, W. Wang, L. Bai, H. Chen, Catal. Sci. Technol., 2019, 9, 2915-2922.

[46] N. Afzali, S. Tangestaninejad, M. Moghadam, V. Mirkhani, A. Mechler, I. Mohammadpoor-Baltork, R. Kardanpour, F. Zadehahmadi, Appl. Organomet. Chem., 2018, 32, e3958.

[47] J. Wang, Y. Zou, Y. Sun, M. Hemgesberg, D. Schaffner, H. Gao, X. Song, W. Zhang, M. Jia, W. R. Thiel, Chin. J. Catal., 2014, 35, 532-539.

[48] A. Gallo, C. Tiozzo, R. PsaroF, F. Carniato, M. Guidotti, J. Catal., 2013, 298, 77-83.

[49] S. Lwin, Y. Li, A. I. Frenkel, I. E. Wachs, ACS Catal., 2016, 6, 3061-3071.

[50] X. Carrier, E. Marceau, H. Carabineiro, V. Rodriguez-Gonzalez, M. Che, Phys. Chem. Chem. Phys., 2009, 11, 7527-7539.

[51] C. Bisio, A. Gallo, R. Psaro, C. Tiozzo, M. Guidotti, F. Carniato, Appl. Catal. A, 2019, 581, 133-142.

[52] J. Hu, K. Li, W. Li, F. Ma, Y. Guo, Appl. Catal. A, 2009, 364, 211-220.

[53] J. Liu, T. Chen, P. Jian, L. Wang, Chin. J. Catal., 2018, 39, 1942-1950

[54] J. Liu, R. Meng, J. Li, P. Jian, L. Wang, R. Jian, Appl. Catal. B, 2019, 254, 214-222.

[55] J. Hafizovic Cavka, S. Jakobsen, U. Olsbye, N. Guillou, C. Lamberti, S. Bordiga, K. P. Lillerud, J. Am. Chem. Soc., 2008, 130, 13850-13851.

[56] C. Ci, H. Liu, L. Yan, Z. Su, ChemistryOpen, 2016, 5, 470-476.

[57] M. Bagherzadeh, L. Tahsini, R. Latifi, L. K. Woo, Inorg. Chim. Acta, 2009, 362, 3698-3702.

[58] M. Bagherzadeh, M. Zare, V. Amani, A. Ellern, L. Keith Woo, Polyhedron, 2013, 53, 223-229.

[59] F. Payami, A. Bezaatpour, H. Eskandari, Appl. Organomet. Chem., 2018, 32, e3986.

[60] P. Jiménez-Lozano, I. Y. Skobelev, O. A. Kholdeeva, J. M. Poblet, J. J. Carbó, Inorg. Chem., 2016, 55, 6080-6084.

[61] N. V. Maksimchuk, G. M. Maksimov, V. Y. Evtushok, I. D. Ivanchikova, Y. A. Chesalov, R. I. Maksimovskaya, O. A. Kholdeeva, A. Solé-Daura, J. M. Poblet, J. J. Carbó, ACS Catal., 2018, 8, 9722-9737.

\title{
溶剂热法合成UiO-66金属有机框架限域的钴取代磷钿酸及其催化烯烃环氧化性能
}

\author{
扈殿文, 宋晓静, 吴淑杰, 杨晓殁, 张浩, 常金瑜, 贾明君 ${ }^{*}$ \\ 吉林大学化学学院, 吉林长春130012
}

摘要: 金属有机框架材料是一类新型晶体孔性材料, 在气体储存、物质分离、非线性光学及催化等领域中具有潜在应用价 值. 其中, 基于锆氧簇和有机配体构筑的锆基金属有机框架材料(ZrMOFs)因其具有更高的结构稳定性而备受关注. 研究表 明, 将多金属氧酸盐(POM)负载在ZrMOFs载体上能够获得一类新型复合材料催化剂. 这类材料具有可调控的酸性和氧化 还原性, 已在一些固体酸催化及选择氧化（包括烯烃环氧化）等反应中表现出优异的催化性能.

多金属氧酸盐通常可以通过简单的浸渍法引入到ZrMOFs载体上, 但这种方法制备的催化剂普遍存在活性组分分散不 均匀且易于在液相催化反应过程中发生活性组分流失的问题. 因此, 当前的研究重点主要集中在如何通过简单有效的制 
备方法获得结构更加稳定、性能更加优异的复合材料催化剂. 近期, 国内外多个研究小组分别报道了采用溶剂热法能够一 步合成出POM@ZrMOFs复合材料, 这类材料的主要特点是POM团簇能够均匀的分散在ZrMOFs孔道中, 从而使其在氧化 脱硫及烯烃选择氧化等反应中表现出更高的稳定性. 考虑到POMs及ZrMOFs种类和结构的多样性, 可以预期这类复合材 料的合成及催化性能研究仍有很大的发展空间.

本文采用溶剂热法将磷钿酸 $\left(\mathrm{PMo}_{12}\right)$ 及钴取代磷钿酸 $\left(\mathrm{PMo}_{11} \mathrm{Co}\right)$ 限域在一类 $\mathrm{ZrMOFs}$ 材料 $(\mathrm{UiO}-66)$ 的孔道中, 得到了两 种复合材料催化剂, 分别记为PMo ${ }_{12} @ U \mathrm{UiO}-66$ 和PMo ${ }_{11} \mathrm{Co} @ \mathrm{UiO}-66$. 通过以叔丁基过氧化氢( $t$ - $\mathrm{BuOOH}$ )为氧化剂烯烃环氧化 反应考察了其催化性能. 相较于PMo12@UiO-66, 含有钴取代磷锄酸的PMo ${ }_{11} \mathrm{Co} @ U \mathrm{UiO}-66$ 杂化材料表现出了更高的催化活 性和稳定性. 催化剂经简单的过滤和洗涤后即可循环使用多次, 且催化性能基本保持不变. 值得一提的是, $\mathrm{PMo}_{11} \mathrm{Co} @$ UiO-66对多种类型烯烃的环氧化反应均表现出较高的催化活性和环氧选择性. 例如, 在加入自由基抑制剂对二 苯酚后, 柠檬烯选择性氧化为柠檬烯-1,2-环氧化物的选择性可以达到 $91 \%$, 性能明显优于文献中报道的其它类型催化剂. 此外, 溶剂种类对PMo ${ }_{11} \mathrm{Co} @ \mathrm{UiO}-66$ 的催化活性有着显著的影响, 在极性相对较强的乙醇、乙腈等溶剂中, 催化剂的活性较 低; 在极性较弱的甲苯、氯仿, 四氯化碳等溶剂中, 催化剂的活性则相对较高. 溶剂极性的差异会影响反应物分子与催化剂 活性中心的接触情况, 继而对催化剂的活性产生较大影响.

采用X射线衍射、氮吸附-脱附、X射线光电子能谱、傅立叶变换红外光谱(FT-IR)等手段对催化反应前后的 PMo ${ }_{11} \mathrm{Co} @$ UiO-66催化剂进行了表征. 结果表明, 在溶剂热法合成的杂化材料催化剂中, 引入的POM团簇能够均匀的分散 在UiO-66框架材料的孔道和笼中; 催化剂反应前后的组成与结构没有发生明显的变化. 结合相关文献报道的结果, 可以认 为杂原子 $\mathrm{Co}$ 的引入能够产生类似于 $\mathrm{Co}-\mathrm{O}-\mathrm{Mo}$ 的新的活性中心, 从而使PMo ${ }_{11} \mathrm{Co} @ \mathrm{UiO}-66$ 表现出更高的催化活性. 催化剂 的高稳定性应主要归因于UiO-66框架对PMo ${ }_{11} \mathrm{Co}$ 团簇的空间限域作用. 这种空间限域作用能够使PMo ${ }_{11} \mathrm{Co}$ 团簇被封装在 UiO-66的八面体笼中, 且二者之间还存在着较强的金属-载体间相互作用. 在后续的工作中, 我们还将继续深入研究 PMo ${ }_{11}$ Co@UiO-66催化剂的活性中心性质及其对分子氧的活化能力, 加深对催化作用机制等问题的理解, 进一步扩大这类 复合材料催化剂的应用范围.

关键词: 多金属氧酸盐; 金属有机框架; 烯烃; 环氧化; 溶剂热合成

收稿日期: 2020-04-08. 接受日期: 2020-05-13. 出版日期: 2021-02-05.

*通讯联系人. 电话: (0431)85155390; 传真: (0431)85168420; 电子信箱: jiamj@jlu.edu.cn

基金来源: 国家自然科学基金(21173100).

本文的电子版全文由Elsevier出版社在ScienceDirect上出版(http://www.sciencedirect.com/science/journal/18722067). 